\title{
De mesianismos impolíticos: Emmanuel Levinas
}

\section{(On impolitical Messianisms: Emmanuel Levinas)}

\author{
Gabriela BALCARCE
}

Recibido: 29 de noviembre de 2012 Aceptado: 8 de abril de 2013

\section{Resumen}

El presente trabajo intenta realizar una lectura del pensamiento de Emmanuel Levinas a través de su ética y, en particular, de su concepción de lo mesiánico. Para ello, indagaremos dos caminos diferentes en torno a la figura del rostro: por un lado, su herencia fenomenológica, por otro lado, sus raíces judaicas. Hacia el final del trabajo sostendremos que el mesianismo levinasiano posee el carácter de lo impolítico, esto es, de un pensamiento que intenta trascender los umbrales de lo político hacia consideraciones críticas.

Palabras clave: Rostro, alteridad, mesianismo.

\begin{abstract}
Absctract
This paper tries to perform a reading of Emmanuel Levinas through its Ethics and, in particular, his conception of the Messianic. To do so, delving two different ways on the 'face' notion: on the one hand, its phenomenological heritage, on the other hand, their Jewish roots. Towards the end of the work we support that Levinasian Messianism has the character of impolitic, i.e., of a thought that attempts to transcend the threshold of political towards a critical considerations.
\end{abstract}

Keywords: Face, Alterity, Messianism. 
Quizá la conciencia de lo universal no comience en el judaísmo por el acuerdo de todos acerca de una verdad, sino por la responsabilidad por todos.

Levinas, 2006

\section{Rostro y fenomenología}

Como cuenta la historia, Emmanuel Levinas fue discípulo de Edmund Husserl. Uno de los tantos discípulos que, explorando el camino del Maestro, avanzó sobre nuevos terrenos que, a su vez, ofrecieron el enriquecimiento de esa compleja tradición que es la fenomenología. Desbaratando sus esquemas de pensamiento en nombre de una experiencia estética (del fenómeno saturado de Marion); de la esencia inefable de la divinidad (Henry); de la reformulación y ampliación de la categoría de corporalidad (Merleau-Ponty); de la dación de ser (Heidegger), de una manera u otra, el gesto que encontramos en estos discípulos $-\mathrm{y}$ del que Levinas será aquí nuestro ejemplo- responde al cuestionamiento del sujeto trascendental husserliano el cual, en su auto-posición, estructuraría la indagación filosófica a partir del privilegio de un paradigma epistemológico.

La auto-posición del sujeto trascendental es alcanzada en la reducción fenomenológica, en palabras de Levinas, "un acto de violencia que el hombre se hace a sí mismo (...) para volver a encontrarse como pensamiento puro." (Levinas 2004, p. 127) Puesta en suspenso al mundo (epojé), la Razón tiende al solipsismo ${ }^{1}$, más aún, el efecto de la reducción trascendental constituiría la neutralización de la independencia de las cosas, convirtiéndolas en fenómenos o en nóemas" (Pérez Quintana 2008 , p. 74). Para Levinas, el conocimiento siempre ha sido interpretado como asimilación:

El objeto iluminado es, a la vez, algo que nos encontramos, pero, por el hecho de que es iluminado, lo encontramos como si saliera de nosotros. No posee extrañeza profunda. Su trascendencia es envuelta en la inmanencia. (Levinas 1980, p. 47)

La desarticulación del sujeto trascendental husserliano supone, en principio, la puesta en cuestión de una noción fundamental, a saber, la de intencionalidad. ${ }^{2} \mathrm{Si}$ bien el proyecto fenomenológico, desde sus inicios, afirmó el Dictum de "volver a las cosas mismas", la elaboración de la categoría de intencionalidad parece romper

\footnotetext{
1 "El solipsismo no es ni una aberración ni un sofisma: es la estructura misma de la razón (...) en razón de la universalidad del conocimiento, es decir, de lo ilimitado de la luz y de la imposibilidad para cualquier cosa de estar afuera”. Levinas (1980, p. 48).

2 "La relación con el otro puede ser investigada como intencionalidad irreductible, incluso si debe terminar por ver en ello la ruptura de la intencionalidad." Levinas (1982, p. 86).
} 
con la posibilidad de un puro análisis de "el aparecer de las cosas" para asumir una función constituyente. Para Levinas, la búsqueda del sentido no reside en una indagación que se centra sobre sí, sino, antes bien, en la posibilidad de una apertura hacia el otro. La idea de infinito ocupa aquí un lugar argumentativo considerable para comprender la diferenciación levinasiana en el experimento crucial que quizás la Quinta Meditación Metafísica nos permite establecer, a propósito de la situación de encuentro con un otro existente. Desbordamiento del contenido o ideatum respecto a la idea y al sujeto que la tiene, la idea de infinito es el testimonio de una exterioridad o trascendencia, en la medida en que no ha podido ser producida por nosotros mismos, según advertía Descartes en la Tercera Meditación Metafisica (Peñalver 2001, p. 68)3. "Su infinición se produce como revelación, como una puesta en mí de su idea." (Levinas 2001, p. 13/ 52). "La violencia que consiste para un espíritu en recibir a un ser que le es inadecuado." (Levinas 2001, p. 11 / 51). Porque la idea de infinito nos vincula con algo que permanece exterior, ella no puede ser incluida en la estela conceptual de la experiencia, si entendemos experiencia como la articulación racional de lo vivido. Derrida afirma, en su herencia de cruces con Levinas:

Lo ineluctable del tercero es la ley en cuestión. Cuestión de la cuestión, cómo dirigirse al otro y desde el otro, al otro del otro, cuestión de una cuestión que, ciertamente no es la primera (llega tras el sí al otro y el sí del otro) pero nada la precede. Nada, y sobre todo, nadie. (Derrida 1997, p. 50)

La fenomenología encuentra así su límite en una apresentación que no puede asumir el carácter de anclaje fenoménico para una empatía analogizante, sino solamente la patentización del otro como Otro. Y "lo otro, lo completamente otro, sólo puede manifestarse como lo que es, antes de la verdad común, en una cierta nomanifestación y en una cierta ausencia." (Derrida 1989, p. 130 / 123). El rostro no es indicio, no es signo de otra cosa como pura representación, sino que se expresa "en persona" al presentarse. Para Levinas, la apresentación de otro cuerpo es la irrupción de un rosto, "sólo de él puede decirse que su fenómeno es una cierta nomanifestación"4, de un rostro que, lejos de ser una suerte de indicio de un igual (a mí-mismo), es el encuentro con el otro:

3 "Esta relación de lo Mismo con lo Otro, sin que la trascendencia de la relación corte las ligaduras que implica una relación, pero sin que estas ligaduras unan en un Todo lo Mismo y lo Otro, está decantada, en efecto, en la situación descrita por Descartes, en la que el 'yo pienso' mantiene con lo Infinito, que no puede de ningún modo contener y del cual está separado, una relación llamada 'idea de lo infinito." Levinas (2001, p. 19/ 72). En el caso de citarse del texto en francés y de su traducción, se pondrán la numeración del texto en francés en primer lugar.

4 Ibid. Alberto Sucasas afirma que, frente a la tradición de la ontología, "para la cual los límites del pensar coinciden por entero con los de la Seinsfrage, el filósofo judío cifra su tarea en 'desbordar ese 
Mi propia fenomenología consistiría en constatar que la identidad del yo y de ese "yo pienso" no es capaz de abarcar al "otro hombre", precisamente por la alteridad y la irreductible trascendencia del otro. (Levinas 1964, p. 308)

La corporalidad del otro como un modo de interpelación: "No se trata de una recaída en el emotivismo, pero tampoco es un cálculo racional (deóntico o consecuencialista). La aísthesis puede verse así como una fuente de ética." (Fonti 2003, p. 64). El rostro es la presentación sensible del Otro, de aquel ser que se me presenta como anterior e inapresable por la conceptualización. Es la presencia de un ser independiente de mi existencia, "la identidad misma de un ser. Se manifiesta en ella a partir de sí mismo, sin concepto" (Levinas 1991, p. 46), oponiendo, de este modo, la significación del rostro a la comprensión y significación que se capta a partir del horizonte en el esquema intencional (Levinas 1991, p. 22). Porque "el concepto supone una anticipación, un horizonte en el que la alteridad se amortigua al enunciarse y dejarse prever". En otros términos, "no hay conceptualidad del encuentro." (Derrida 1989, p. 141/129)

En De otro modo que ser, o más allá de la esencia, Levinas explica este pensamiento de la trascendencia del otro a partir de la figura de la huella, una figura desarrollada anteriormente en "La huella del otro"5, texto del cual se nutre Derrida, haciendo de esta noción uno de los núcleos centrales de la deconstrucción desde $D e$ la gramatología. En cuanto a la noción levinasiana, nos interesa destacar aquí que ella es la "proximidad anárquica de una singularidad sin mediación de principio", la huella es irreductible a la tematización de la conciencia. "Este modo de pasar inquietando el presente sin dejar cercarse por el arché, marcando con surcos la claridad de lo ostensible", "sin medida común con el presente" y no compaginable con él (Levinas 1978, p. 158 / 165). Parece entonces, que en la temática del otro, la trascendencia no se presenta para desbaratar solamente al Mismo sino también a la temporalidad de la mismidad. Un out of joint del presente -en términos derrideanos-, un desquicio del tiempo entendido como proyección de la mismidad. Porque el elemento de la relación con el otro es el tiempo (Levinas 1982 a, p. 52), allí donde la extrañeza del futuro nunca puede inscribirse en el ámbito de una protensión. "El tiempo no es el hecho de un sujeto aislado sólo, sino que es la relación misma del sujeto con el otro." Inconmensurabilidad de la conciencia, la huella es "una asignación más de parte del otro, una responsabilidad frente a los hombres que ni siquiera conocemos." (Levinas 1980, p. 17)6 ${ }^{6}$ Y esta marca es más antigua que el a prio-

\footnotetext{
juego de luces -esa fenomenología- y consumar acontecimientos cuya significación última -contrariamente a la concepción heideggeriana -no consiste en develar." Sucasas (2006, pp. 173-174). El subrayado es de A.S.

5 E. Levinas, « La trace de l'autre » citado en la Derrida (1967, p. 91, nota n 33 ).

${ }^{6}$ La herencia rosenzweigeana del "Neues Denken" es notable: sólo en la consideración del tiempo, en la apertura a la temporalidad puede, aparecer el otro.
} 
$r i$, afirma radicalmente Levinas, más antigua, porque es anterior a todo Mismo en tanto exterior, trascendente. Sin embargo, la resistencia no debe ser pensada aquí como la nota esencial de esta caracterización en la medida en que:

Lo Otro metafísico es otro como una alteridad que no es formal, con una alteridad que no es simple revés de una identidad, ni de una alteridad hecha de resistencia al Mismo, sino con una alteridad anterior a toda iniciativa, a todo imperialismo del Mismo. (Levinas 2001, p. 29 / 62. El subrayado es nuestro)

Siguiendo la inspiración cartesiana, la huella es esa marca de la trascendencia que obsesiona al reino inmanente del Principio. El primado de un lógos kerigmático que moldea a las cosas como si ellas fueran pura materia informada, ordenándolas bajo un sistema. Lógica de la apropiación de toda materia, al servicio de una idealidad o lo que denomina "el ser en potencia" (Levinas 1978, p. 173/177). Esta última expresión se encuentra en consonancia con la crítica de Levinas a la ontología fundamental heideggeriana. Sin embargo, creemos que ella nos permite pensar en un terreno incluso más vasto de intervención: nos referimos a la reconstrucción que Levinas realiza de la metafísica y de la continuidad que la fenomenología representa en más de un punto con ella: la lógica del Mismo, coincidente no solamente con la egología husserliana y con la ontología heideggeriana, sino, antes bien, con cierto esquematismo que nuestro autor reconstruye de las nociones centrales que característicamente la modernidad negó en torno a la singularidad y a la alteridad. Todas estas filosofías comparten una lógica sistematizante del Principio sobre lo finito, lo material y aquello que varía. ${ }^{7}$

Es importante aquí no confundir los usos de "finito" e "infinito" y sus respectivos campos problemáticos de intervención. Por un lado, la finitud podría ser pensada en consonancia con la reivindicación de lo que se resiste a la captura del Principio. En este sentido, finitud y diferir encontrarían un lazo conceptual. Por su parte, la temática de la infinitud se relaciona con la crítica a las filosofías de la inmanencia, siendo el infinito - como ya lo hemos señalado- la huella de una trascendencia no mediada, pero inscripta en el ser finito.

Si regresamos a Totalidad e Infinito, en el desarrollo de esta historia del Principio, Levinas distingue tres momentos característicos que encuentra en Sócrates, Berkeley y Heidegger. El imperio histórico de lo Mismo, cuya operación nuclear sería la reducción o neutralización de la alteridad, se encuentra consignada en tres momentos coincidentes con tres operaciones: el racionalismo socrático como inicio del filosofar egológico (Peñalver 2001, p. 64); el idealismo de Berkeley, que

\footnotetext{
7 "Incapaces de responder a lo otro en su ser y en su sentido, fenomenología y ontología serían, pues, filosofías de la violencia. A través de ellas, toda la tradición filosófica en su sentido profundo estaría ligada a la opresión y el totalitarismo de lo mismo." Derrida (1967, p. 136 / 124).
} 
habría delimitado la relación entre sujeto-objeto, haciendo del objeto el producto de la sensación, estableciendo la coincidencia de lo vivido consigo mismo como revelamiento de la coincidencia del pensamiento con el ente. (Levinas 2001, p. 15 / 68). Pero es en el tercer momento donde la neutralización metafísica opera de manera más eficiente. Bajo el signo de la ontología fundamental, Heidegger es el representante de una filosofía de la potencia y con ello, de la totalidad y de la tiranía:

La ontología, como filosofía primera, es una filosofía de la potencia. Converge en el Estado y la no-violencia de la totalidad, sin precaverse de la violencia de la que vive esa no-violencia y que aparece en la tiranía del Estado. (Levinas 2001, p. 16 / 69-70)

Porque para conocer al ente, habrá que haber comprendido el ser del ente, la exigencia heideggeriana se vuelca sobre la importancia de un retirarse de la absorción mundana, para tener acceso a una idealidad que, aunque epocal, es unificadora y totalizante. Unidad ontológica, pero también política. El ser antes que el ente, "el primado es de entrada principio y jefe." (Levinas 2001, p. 16 / 69-70) En cuanto a la implicación aquí sugerida entre ontología y tiranía estatal, creemos que será más interesante desarrollar algunas nociones más de la filosofía levinasiana para analizar desde un contexto más adecuado lo allí afirmado. La metafísica y la ontología son, en última instancia, el cuestionamiento del Otro por el Mismo, "del Otro por Mí" (Levinas 2001, p. 34 / 67). Pero, para Levinas, la pregunta se revela como respuesta, es por ello que la ética es aquí una filosofía primera, porque lo primero es la relación con el Otro, un Otro que ningún sí-mismo puede simplemente esquivar en el ejercicio de su afirmación. El modo en que el Otro se presenta es el rostro, que "supera la idea de lo Otro en mí" (Levinas 2001, p. 42 / 74), porque el rostro inaugura una expresión, anterior a la Sinngebung, es inmediato, es interpelación en un cara-a-cara. ${ }^{8}$

La temática del rostro nos conduce, no obstante, a un más allá de la filosofía también, hacia otra dirección de indagación. En las páginas que siguen analizaremos la cuestión del rostro desde la perspectiva judía, la otra gran fuente de la obra levinasiana.

\section{Cara a cara}

En el hebreo bíblico, el término "rostros", panim (פנם), plural, aparece en una miríada de usos diferentes que parten de un uso primario que remite simplemente al rostro (פנה, pané). Sin embargo, el recorrido semántico de este vocablo es extre-

\footnotetext{
8 Una interesante etimología latina de la invocación: evocare significaría "hacer salir llamando" (Corominas, Breve Diccionario etimológico de la Lengua castellana).
} 
madamente interesante. El primer desplazamiento nos conduce a la noción de "persona", que nos acercaría desde un principio a la descripción levinasiana de la apresentación del rostro, "en persona". Pero es en los verbos donde el juego lingüístico hebreo florece enriqueciendo la terminología: la acción (paná) de "comparecer frente a alguien", de "dirigirse a alguien, incluso de esperar a alguien". El término bíblico llega a cubrir el espectro de expresiones que son traducidas por "postrarse" en señal de respeto, reverencia y obediencia. En los casos en que esto sucede estamos siempre en presencia de una asimetría, mundana o divina, en la que el hombre "se arrodilla inclinando su rostro". Frente al rey:

Y dieron aviso al rey, diciendo: He aquí el profeta Natán; el cual, cuando llegó frente al rey, se postró delante del rey inclinando su rostro a tierra (I Reyes 1:27.)

Y cuando Abigail vio a David, se bajó prontamente del asno, y postrándose sobre su rostro delante de David, se inclinó a tierra. (I Samuel 25:23)

Pero este comparecer también puede ser frente a la divinidad. Frente a Dios, en el relato de Éxodo, cuando Moisés recibe el mensaje de Dios ("Yo soy el Dios de tu padre, Dios de Abraham, Dios de Isaac y Dios de Jacob" en Éxodo 3:6): "Entonces Moisés cubrió su rostro, porque tuvo miedo de mirar a Dios."

Por otra parte, panim cobra la forma elusiva de designar "el indefinible y velado rostro de Yhwh". La principal fuente de este uso es la literatura profética, aunque el Éxodo también ocupa un lugar relevante (estableciendo una y otra vez el diálogo profético con la analogía de la liberación terrenal del Éxodo). En cuanto a la literatura profética, podemos encontrar el panim tanto en la condena como en la promesa divina. La condena de Ezequiel 7: 22: "Y apartaré de ellos mi rostro"; o la de Jeremías (18:17): "Como el viento solano los esparciré delante del enemigo; les mostraré las espaldas y no el rostro, en el día de su perdición”; pero también la promesa del resplandecer del rostro: "Jehová haga resplandecer su rostro sobre ti, y tenga de ti misericordia." (Números 6:25) "Esperaré, pues, a Jehová, el cual escondió su rostro de la casa de Jacob, y en él confiaré" (Isaías 8:17). ${ }^{9}$

El rostro como un modo de encontrarse con el otro o con lo Otro: Dios. Paním como nombre de otro nombre, impronunciable, cuya trascendencia nos insta a respetar esa distancia. En la observancia de esa lejanía, de la separación inicial, el rostro abre la cercanía de una relación sin relación (religión), cuya espera se torna

\footnotetext{
9 También Jacob es una figura interesante en este punto, dado que en el momento crucial de su vida, aquel en el cual se produce el viraje -incluso la transformación de su nombre- que al finalizar la lucha con el ángel que enderezaría su nombre, llamó Peniel (פניאל, literalmente, "rostro de Dios") a aquel lugar, para recordar el encuentro donde estuvo con "Dios cara a cara habiendo salido con vida" (Génesis 32:30).
} 
paradójicamente una respuesta. Muy cerca de Hermann Cohen, el Mesías, lejos de representar el ideal de lo político arraigado en la idea de soberanía, aparece en el terreno de las relaciones intersubjetivas. Porque es en el ámbito de la ética donde se dirime esta posibilidad, una posibilidad que no encarna lo mesiánico en una persona, sino en cualquiera de ellas, incluso en la mía:

Todas las personas son el Mesías (...). El mesianismo no es, por tanto, la certeza de la llegada de un hombre que detiene la historia. Es mi poder de soportar el sufrimiento de todos. Es el instante en el que reconozco ese poder y mi responsabilidad universal. (Levinas 1976, p. $139 / 143$ )

Apenas entrevisto, solamente (Mallet 1998, p. 173), el rostro abre la grieta de la circularidad de un sí-mismo, que sólo se pierde para ser recobrado. Y en este abrir se conjuga la cercanía del otro, del rostro de un otro inefable, pero también del nuestro, que está llamado a la responsabilidad y el respeto. "Una mirada que suplica y exige" (Levinas 2001, p. 73 / 98) y que, sin embargo, es por sí misma, no responde a mi sistema, de manera que no puedo simplemente apropiarme de él. "Como si la piel fuese la huella de su propio vacío" (Levinas 1978, p. 144 / 156), lo inmediato del rosto impide la representación porque se encuentra arrancado del mundo y de todo horizonte. Proximidad de lo absolutamente lejano:

(H)uella de un paso que jamás se ha hecho presente, posiblemente nada cuyo exceso respecto a la nada pura -una diferencia infinitesimal -está en mi no-indiferencia a la vista del prójimo en la que yo obedezco, como orden dirigida a mí, a una orden que arroja "un grano de locura" en la universalidad del Yo; orden dirigida a mí que respondo ante aquel del que soy responsable, sin que lo pre-original llegue a tomar su origen en un presente propio del aparecer. (Levinas 1978, p. 145/157)

Las "miles de nadas" de La Estrella rosenzweigeana parecen evocarse aquí. Miles de excesos que rompen cualquier unidad de la experiencia. La unidad es algo a posteriori $\mathrm{y}$, por tanto, un sueño irrealizable develado. El punto de partida no es una abstracción radical, así como tampoco la consciencia pura. A diferencia de las filosofías del Presupuesto que conjuran el out of joint de un fenómeno paradojal, el rostro del prójimo es el aparecer de lo invisible, el señalamiento de la disparidad. Frente a la revelación del fundamento, el rostro estructura el significante como unopara-el-otro, como un significante más allá del sistema, sin comienzo, an-árquico (Levinas 1978, p. 212/209). La deposición de esta soberanía del Yo es, a juicio de nuestro autor, la relación con el otro (Levinas 1982a, p. 50). La acogida de la alteridad es condición de todo pensamiento, y más aún como condición de todo Yo. Rebasa toda posibilidad de tematización, abriendo al Yo a partir de la idea de infinito y rompiendo con la posibilidad de la totalidad. Levinas señala, no obstante, en 
esta historia un gran antecedente en la figura de Franz Rosenzweig. 10: "(E)s el escándalo de la muerte, aquel que desintegra la síntesis universal" (Levinas 1982c, p. 13). Contra la tesis hegeliana de incluir al otro a partir de una negatividad apresable-sintetizable-dialectizable en una totalidad, la posición levinasiana a este respecto es la postulación de una alteridad no reductible a lo Mismo, un Otro que se presenta en la forma sensible del rostro, en el cara-a-cara:

La Estrella de la Redención que rompe la totalidad en la angustia de la nada, no reúne al ente humano al cuidado de su ser mismo; ella lo conduce a la relación frontal con el otro hombre. (Levinas 1982c, p. 15)

La irreductibilidad del otro a una negatividad, el rebasamiento de la ontología que se presenta en la inaprensibilidad del otro, del rostro del otro en su epifanía -y que permanece como condición originaria-, es lo que constituye la hospitalidad para Levinas. La hospitalidad es, pues, la situación de puesta en contacto con un otro no tematizable que se patentiza como precedencia y que, por tanto, exige una responsabilidad no deslindable. Es por ello que Derrida señala que Totalidad e infinito es fundamentalmente (y aún cuando no sea el término más recurrente al interior de sus páginas) un tratado sobre la hospitalidad (Derrida 1997, p. 47). La hospitalidad es este sí al otro, en tanto significa la pura afirmación de una patencia originaria. El sí al otro es la afirmación de una alteridad que me precede y con la cual me encuentro desde siempre en una situación de deuda no saldable, aun cuando la niegue o quiera capturarla bajo un horizonte intersubjetivo:

Es extremadamente importante saber si la sociedad, en el sentido corriente del término, es el resultado de una limitación del principio que dice que el hombre es un lobo para el hombre, o si, por el contrario, resulta de la limitación del principio según el cual el hombre es para el hombre. (Levinas 1982 a, p. 69. El subrayado es de E.L.)

La respuesta es clara en este punto: la figura del mesianismo coincide con la intersubjetividad ética, marcada por la responsabilidad con el otro (Beckert (2008), p. 103).

Quizás podamos decir que Levinas es aquel que, en los extraños caminos que la fenomenología efectivamente asumió y abrió en el espacio de la tradición husserliana11 -y con ello, gran parte de las categorías de la filosofía moderna en torno a

10 "En lo que a mí concierne, donde por primera vez he encontrado una crítica radical de la totalidad ha sido en la filosofía de Franz Rosenzweig." Levinas (1982a, p. 64). "En Rosenzweig hay, pues, un estallido de la totalidad y la apertura de una vía absolutamente distinta en la búsqueda del sentido." Levinas (1982a, p. 65).

11 "Por la filosofía de Husserl y las herejías por ella provocadas" p. Ricoeur (1953). En un texto publicado en homenaje a Emmanuel Levinas, Jean-Luc Nancy realiza un fino análisis sobre el estatuto 
la epistemología (en tanto metafísica moderna) - puso en contacto a ésta con nociones centrales del judaísmo, como lo son el otro, la viuda, el extranjero y el huérfano; incluso el rostro (panim) mismo como un comparecer. 12 Un rostro que, en su opacidad, asume el carácter de la invocación, un llamado a la heteronomía. Lo infinito es el rostro (Biset (2012), p. 85). Lo primero es la ética y la razón de ello es la precedencia del Otro. En nombre de una alteridad irrecusable, de la pura trascendencia que es Dios, la ética es el terreno de lo humano que se juega en este mundo, pero cuyas reglas pertenecen al nivel del llamado de lo incondicional. El ser-en-elmundo no se descubre simplemente como ser-con-otros, sino que, en dicho reconocimiento encuentra una obligación que antecede a la afirmación del sí-mismo.

(H)ay alguien que llama, alguien que llama en el rostro del otro, que obliga sin fuerza. La autoridad no es en absoluto la posesión de la fuerza. Es una obligación sin fuerza. (Levinas 2008, p. 23)

\section{Sobre mesianismos impolíticos}

Cabe destacar la fuerza del discurso rabínico, en detrimento de otras voces judías, en la lectura levinasiana de lo mesiánico. Esto, sin embargo, no implica necesariamente una unidad de interpretación sino, antes bien, la recuperación de una metodología que enfrenta tesis y las explora tan comprometidamente como para llegar, incluso, hasta sus últimas consecuencias. Levinas analiza y ensaya lecturas del Talmud. Oscilando entre la filosofía y el polifonismo rabínico impreso en esta obra monumental, arriesga -o quizás debamos utilizar la expresión derrideana inventauna manera de comprender el mesianismo como la posibilidad de repensar cierta sociabilidad del lo social.

En la encrucijada entre los registros discursivos en los que interviene la temática de lo mesiánico, Levinas intenta realizar un comentario aclaratorio acerca de aquello que comúnmente se entendería por tal noción:

fenomenológico de la aparición del otro, extrayendo de dicho seguimiento el siguiente cuestionamiento: « Le soi selon lequel se montre le phénomène (en général ou d'Autre) reste donc, en tant que tel, énigmatique et indéterminé. ». La hipótesis que, a partir de esta pregunta, esboza Nancy es que, frente a la apropiación del sí mismo, correspondiente a la lógica de la mismidad, la otredad, por su parte reconduciría la cuestión del sí como donación (se donner): " La question de savoir comment le visage se montre revient donc à déterminer comment il se donne. » (Nancy 1988, p. 12).

12 Sucasas sostiene en este punto una coincidencia u homología estructural entre la revelación veterotestamentaria y la epifanía del rostro: "Yahweh, revelándose, mantiene su naturaleza de deus absconditus (...). El precio de la insobornable trascendencia de Yahweh es que la revelación lo sea de un misterio insondable. Sólo el respeto a la indivisibilidad divina preserva al fiel judío de la tentación idolátrica" (Cf. Sucasas 2006, p. 174). 
Poco y nada podemos decir del Mesías si pretendemos representarlo como una persona que, milagrosamente, viene a poner fin a la violencia que domina el mundo, a la injusticia y a las contradicciones que desgarran a la humanidad, aun cuando éstas tienen su origen en la naturaleza de la humanidad y en la Naturaleza como tal. (Levinas 1976, p. 95/111)

La dimensión del milagro y del catastrofismo son dejadas de lado en favor de una perspectiva antipersonal (no hay una persona del Mesías) en continuidad con Maimónides y Cohen. Para ampliar esta caracterización nos gustaría, en este punto, abocarnos al análisis de Levinas de un pasaje talmúdico que versa sobre la era mesiánica. La fuente judía aquí es el Tratado de Sanhedrín 99 a, que nos permitimos citar parcialmente:

Rabí Jiyá ben Abba dijo, en nombre de Rabí Iojanán: “Todos los profetas, sin excepción, sólo han profetizado para la época mesiánica. En cuanto al mundo futuro, ningún ojo lo ha visto fuera de Ti, Oh Señor, que obrarás para aquel que te espera.

Este texto, perteneciente al tejido del texto talmúdico, contiene el guiño de un versículo bíblico: "Nunca ningún ojo humano ha visto a otro dios más que a Ti obrar de ese modo a favor de sus fieles." (Isaías 64:3) Aquí encontramos, no obstante, la mixtura que el pilpul produce en los textos de comentario. Los comentarios y las fuentes se compenetran en una nueva textualidad, que avanza sobre la escritura bíblica en la búsqueda de la reinvención de una tradición que se constituye en la forma de la apertura en el instante del peligro más próximo (en palabras benjaminianas). Levinas comienza el análisis de este pasaje considerando la distinción clásica judía entre "reino futuro" y "reino mesiánico": Se sabe que a los judios les estaba prohibido escrutar el futuro, recordaba Benjamin hacia el final de sus Tesis. La promesa mesiánica no representa simplemente el anuncio de una predicción, lo cual sería, a juicio de Rabí Hillel, una mera "delegación” (Levinas 1976, p. 130/137), sino que justamente es en el reverso de esta imagen, donde Levinas nos arroja la lectura de tal separación:

¿Qué es concretamente un pueblo que sólo tiene como rey a Dios, sino una existencia, en la que nada se hace por delegación, en la que cada uno participa por entero en lo que eligió y está completamente presente en su elección? Relación directa entre el hombre y Dios sin mediación política. Esto supera a un mesianismo todavía político que según la página siguiente del Tratado de Sanhedrín, sólo tendrá duración limitada. (...) La salvación no representa el fin de la historia ni su conclusión. Ella es posible en todo momento. (Levinas 1976, p. 131 / 137. El subrayado es de E.L)

Su posición se inclina hacia el terreno de la responsabilidad de la elección divina frente a una elección que nos interpela a responder. La lectura filosófica del 
mesianismo judío aquí consignada interviene sobre una distinción central, a saber, en el terreno de la ética y lo social, por una parte y, por otro, la política y la filosofía de la historia. Esta distinción puede traducirse también en el enfrentamiento entre alteridad y mismidad, o entre ética y ontología.

Frente a la intervención divina de una Providencia que dejaría al hombre a un costado de su propio destino, lo que aquí encontramos es un compromiso absoluto, una existencia que es elegida para no delegar. No es al fin del mundo hacia donde la flecha mesiánica apunta, sino a la posibilidad de una transformación que se encuentra una y otra vez en este mundo. Y este destino no es nunca individual, desde el mismo momento en que un pensamiento de la trascendencia-como hemos observado a propósito de las nociones de infinito y huella- se manifiesta desde el inicio como un pensamiento del más-que-uno. Sin embargo, creemos que la caracterización levianasiana de un "mesianismo sin mediación" o de un "más allá" permite encontrar el contenido impolítico de este pensamiento.

Podríamos quizás afirmar entonces que, en esta historia, hay dos tiempos. El tiempo mesiánico de lo político, aquel que converge en las promesas políticas y sociales de los profetas, donde la relación con lo divino atraviesa la relación con los hombres, coincidiendo con la justicia social (Derrida 1967, p. 40 / 65) y otro momento, la escatología quizás, donde la mediación política ha sido disuelta, un "más allá" que excede el terreno de lo económico, donde el otro ya no es el pobre sino como amigo (Levinas 1976, p. 97/115), quizás, aquella "armonía de las naciones" con la que soñaba Cohen desde su lectura kantiana.

Con ello no queremos señalar el abandono de la preocupación política presente, sino antes bien, delimitar un esfuerzo de pensamiento "por sustraerse del terror producido por la política de Estado, sugiriendo una experiencia comunitaria" (Galindo 2005, p. 30) ${ }^{13}$ que impida la articulación totalizante bajo la figura del Estado. La categoría que aparece en escena es la de soberanía, vinculada de manera directa con las críticas a lo Mismo que hemos intentado aquí esbozar. Un mesianismo impolítico, que sin dejar de lado en absoluto el interés por lo político y lo social, abriría un espacio de cuestionamiento, incluso de posibilidad de enjuiciamiento de la historia. ${ }^{14}$

La encrucijada, sin embargo, aparece en la oscilación levinasiana entre un "ideal de armonía de las naciones" - aunque sólo fuera bajo la forma de un acerca-

\footnotetext{
13 Es importante destacar que Galindo sigue los lineamientos de la elaboración espositeana de lo impolítico, en el famoso libro Categorías de lo impolítico (2006), sin embargo, habría que aclarar que en el caso levinasiano, esta impoliticidad no representa un corrimiento de lo político a lo ontológico sino una apertura a la ética como punto de anclaje y de revisión de lo político. Lo impolítico ejerce aquí fundamentalmente el carácter de la crítica a la onto-política.

14 "Levinas describe así la historia como ceguera a lo otro y laboriosa procesión de lo mismo" Derrida $(1989$, p. $139 / 127)$.
} 
miento infinito- y la exigencia de un "más allá" propio de un pensamiento de la trascendencia.

$$
* * *
$$

¿Cómo puede un pueblo ser "sin mediación política"? ¿Sigue siendo un pueblo? Podemos, desde este cuestionamiento, abrir dos vías de respuesta. Por un lado, el pueblo de Israel como resto mesiánico que resiste a la totalización de la Historia Universal (del Mismo), en la máxima cercanía de Rosenzweig. ${ }^{15}$ Pero, por otra parte, si retomamos la distinción sugerida anteriormente entre ética y política, la lectura mesiánica de Levinas parecería inscribirse en lo que él mismo denomina "la sociabilidad de lo social". En este sentido, la desapropiación del Mismo como apertura y afirmación de lo Otro podría ser el núcleo de este proceder de manera ejemplar. La desposesión es el encuentro con el rostro.

A juicio de Levinas, para el judaísmo, la proximidad misma de Dios sería inseparable de la transformación ética de lo social y coincidiría con la desaparición de la servidumbre y de la dominación en la estructura de lo social. (Levinas 1982b, p. 26) El hombre es el punto por donde pasa la trascendencia porque la infinición impide el retorno, develando la errancia como momento inicial, o lo que es lo mismo, no habría habido un lugar desde el principio asegurado, cuyo destino sería el retorno a esa Tierra, tan prometida. "Toda institución razonable es desarraigo" (1982a , p. 24). Para Levinas, la elección no está hecha de privilegios, sino de responsabilidades 16 :

\footnotetext{
15 A juicio de Rosenzweig, el pueblo judío cumple un mandato extra-histórico, que se articula en una nueva filosofía de la historia, aquella que da cuenta del carácter finito de toda configuración histórico-política. En este sentido, quizás podamos decir que La Estrella es un libro judío, pero judío entendido en el sentido que aquí consignamos a partir de la noción de "resto" y que Bensussan describe del siguiente modo: "La profunda extra-historicidad, y no simplemente contingente, del 'pueblo judío' (...) en tanto habitante de una eternidad anticipada, extranjero a las leyes, la tierra y la lengua de los pueblos entre los que lleva una existencia separada. La extra-historicidad judía conlleva un pensamiento de la historia, del Estado y lo político (...) Significa efectivamente la imposibilidad de que la totalidad histórica llegue a totalizarse sin resto". (Bensussan 2009, p. 14)

16 Como nos recuerda Emanuel Biset: "Levinas aborda la relación de Sinaí con la hospitalidad, retomando una pregunta que Levinas realiza en La hora de las naciones, específicamente en el texto Las naciones y la presencia de Israel. Allí pregunta Levinas por la posibilidad de un reconocimiento de la Torá antes de Sinaí. Escribe Levinas: “¿La historia de las naciones no ha sido ya de algún modo esta glorificación de lo Eterno en Israel que se mide por una apertura de su solidaridad nacional al otro hombre, al extranjero? Un reconocimiento de la Torá antes de Sinaí» (Levinas 1988, p. 112)" Biset (2012, p. 228).
} 
Es la ruptura del ser allí donde se produce el don con las manos llenas, en lugar de luchas y rapiñas. Ese es el sentido primero de la elección, elección que ciertamente puede degradarse en orgullo, pero que originalmente expresa la conciencia de una acusación irrecusable de la que vive la ética y en la que lo irrecusable de la asignación aísla al responsable. (Levinas 1982b, p. 216)

La radicalidad del planteo en este punto nos arroja el corolario esperado, la exclusión de la representación como esquema de relación metafísica entre lo Mismo y lo Otro" (Peñalver 2001, p. 62). ${ }^{17}$ Con Levinas se nos presenta la imposibilidad absoluta de deducir una politica a partir de la perspectiva ética (Bensussan 2008, p. 34). Mientras la política se articula alrededor de nociones tales como las de autonomía y nación - y su correspondencia con la guerra-, confrontan con el ideal de una "paz mesiánica". Pero, al mismo tiempo, "la escatología, en tanto que el "más allá" de la historia, arranca a los seres a la jurisdicción de la historia y del porvenir, los interpela en su plena responsabilidad y los convoca" (Levinas 2001, p. 12/49). En cada instante, la historia puede ser puesta en tela de juicio, juicio que no es el final de todos ellos, el Juicio Final, sino "el juicio de todos los momentos en el tiempo en que se juzgan a los vivos" (2001, p. 12/50):

No recibir nada del otro sino lo que está en mí, como si desde toda la eternidad yo tuviera lo que me viene de afuera. No recibir nada o ser libre. La libertad no se parece a la caprichosa espontaneidad del libre albedrío. Su sentido último reside en esta permanencia en lo Mismo, que es Razón. El conocimiento es el despliegue de esta identidad. Es libertad. Que la razón sea a fin de cuentas la manifestación de una libertad, que neutraliza lo otro y que lo engloba, no puede sorprender, desde que se dijo que la razón soberana sólo se conoce a sí misma, sin que alguna alteridad la limite. (2001, pp. 13-14/67)

Porque la Justicia "precede y condiciona el esplendor visible", del mismo modo que uno de los primeros nombres del Mesías, Yinón, quien "antes del sol, su nombre era Yinón” (1976, p. 133/139); pero también es la respuesta a la elección, la que nos acerca a lo mesiánico y al abandono de una consideración mítica, "para pensar una forma de vocación personal entre los hombres" (2001, p. 136/141). Todas las personas son el Mesias:

El Mesías, es decir, la obligación de ocuparse del otro, es mi tarea. En mi individualidad, en mi unicidad, hay esto: yo soy posiblemente el Mesías. (2008, p. 26)

\footnotetext{
17 Si bien la temática del monoteísmo parecería permitir la articulación de una unidad, ella no parecería anclarse en una función representativa, mediadora. En este sentido, pueden esbozarse una serie de problemas desde una indagación más cercana a la filosofía política, a saber, la pregunta por un esquema de mediación y representación política.
} 
La primera relación del hombre es con otro hombre (1976, p. 44/68) y el judío, afirma nuestro autor, descubre esto antes "que los paisajes y las ciudades", antes que el territorio. El Mesías es el justo que sufre y que carga sobre sí el dolor de la Humanidad. Como señala Peñalver, "la metafísica del rostro es incompatible con la Filosofía de la Historia" (2001, p. 43) como totalización racional, dado que, frente a la ética del otro, la filosofía del ser nos arroja a la experiencia de la guerra. El estado de guerra, afirma Levinas, suspende la moral porque anula los imperativos incondicionales en lo provisorio de una proyección anticipada sobre la base de los actos de los hombres (Levinas 2001, p. vii / 47). Es por ello que política y guerra se copertenecen a partir del enclave de la Razón occidental, de una razón como cálculo anticipador, que recorrería la estela metafísica hasta el concepto mismo de horizonticidad husserliana, así como las bases del pensamiento político moderno presentes en Hobbes, en la caracterización de un hombre al servicio de una racionalidad como cálculo, anticipante, cuyo estadio natural implicaría una guerra de todos contra todos.

El ideal filosófico occidental habría consistido en el ejercicio de apropiación de todo rostro, de toda alteridad. Frente a la fuerza de la política y la historia, la debilidad del rostro abre el espacio de una "obligación sin fuerza", obligación que, tanto para Levinas como para Benjamin, nos ayudarán a comprender la necesidad de cierta exterioridad o heterogeneidad como posibilidad de un juicio histórico o, al menos, de un interrupción de lo histórico:

No digo en ningún caso que triunfe -el Mesías no viene-, pero este Yo sí ha oído la invocación, por esa vocación es único y uno, es la individuación. Yo no tengo filosofía de la historia que pueda consolar todos los abusos, incluso de la relación con un rostro. Lo que me ha importado es interrumpir la gravedad del ser que se ocupa de sí mismo, la posibilidad de tener en cuenta, desarrollar una bondad por otro ser, ocuparse de su muerte antes que de la propia. (Levinas 2008, p. 27. El subrayado es nuestro)

Volviendo a la distinción entre reino mesiánico y fin de los tiempos, el mesianismo se presenta todavía como una fase histórica, pero que abre a un "más allá de lo histórico", que se articula en la vinculación judía entre lo divino y lo terrenal. En términos políticos, el mesianismo no suprimiría al Estado sino que abriría una grieta en el ejercicio de su adoración misma (Levinas (1982b), p. 268). En este sentido, Levinas no es un gran difusor del sionismo, sino que piensa que éste último pensamiento constituye la opción por el Estado del César (Levinas (1982b), p. 272), es decir, por una Realpolitik en detrimento del "más allá" de una moralidad que rompa con las cadenas de un suceder histórico olvidado de su responsabilidad inicial. Es necesaria esta debilidad, señala Levinas. Si soberanía y pueblo articulan un nexo conceptual, Levinas insiste en la asimetría que nos consigna a la respuesta y, por tanto, a la alteridad del llamado: 
Pueblo llamado a salir a su vez del concepto de Yo, de su extensión en el pueblo, para responder con responsabilidad: yo, es decir, heme aquí para los otros; para perder radicalmente su puesto o su abrigo en el ser y entrar en la ubiquidad (...). Heme aquí para los otros: respuesta enorme, cuya desmesura se atenúa con hipocresía desde su entrada en mis orejas propias (...). (Levinas 1978, p. 282/266)

\section{Referencias bibliográficas}

Alford, C. (2004): "Levinas and the Political" en Political Theory, vol. 32, $\mathrm{N}^{\circ} 2$ (Apr., 2004), pp. 146-171.

BECKERT, C. (2008): "O Messias sou eu: Reflexões sobre o messianismo de Emmanuel Levinas" em Reflexão. Revista Semestral de Filosofia, Ano 33 N $^{\circ}$ 94, PUC.

Benjamin, W. (2009), "Sobre el concepto de historia" en Estética y política. Walter Benjamin, trad. Tomas Joaquín Bartoletti y Julián Fava, Buenos Aires, Las Cuarenta.

Bensussan, G. (2008): "Intransitividad de la ética" en Alonso Martos, A., (ed.), Emmanuel Levinas. La filosofía como ética, Universitat de València, PUV.

Bensussan, G. (2009): Franz Rosenzweig. Existencia y filosofia, trad. Daniel Barreto González y Helenca Santana Sánchez, Madrid, Anthropos.

Biset, E. (2012): Violencia, justicia y política. Una lectura de Jacques Derrida, Córdoba, Eduvim.

CoHen, H. (2004): La religión de la razón desde las fuentes del judaísmo, trad. Andrés Ancona Quiroz, Barcelona, Anthropos.

Derrida, J. (1967): De la Grammatologie, Paris, Minuit, 1967. De la Gramatología, trad. Oscar del Barco y Conrado Ceretti, México, Siglo XXI, 1985.

Derrida, J. (1989): "Violencia y metafísica. Ensayo sobre Emmanuel Levinas" en La Escritura y la Diferencia, trad. p. Peñalver, Barcelona, Anthropos.

Derrida, J. (1997): Adieu à Emmanuel Levinas, Paris, Galilée. Adiós a Emmanuel Lévinas seguido de Palabra de acogida, Madrid, Trotta, 1998.

FonTI, D. (2003): "Violencias faciales: Bacon y Levinas" en Nombres. Revista de Filosofía, Córdoba, año XIII, n 18, diciembre de 2003.

Galindo Hervás, A. (2005): Política y Mesianismo. Giorgio Agamben, Madrid, Biblioteca Nueva.

LeVInAs, E. (1988): À l'heure des nations, Paris, Minuit.

Levinas, E. (1978) Autrement qu'être ou au-delà de l'essence, Paris, Livre de Poche. De otro modo que ser, o más allá de la esencia, Salamanca, Sígueme, 1995. 
Levinas, E. (1976) : Difficile Liberté. Essais sur le judaïsme, Livre de Poche, Paris. Dificil libertad, Buenos Aires, Lilmod, 2005.

LEvinAs, E. (1964) : «Entretien avec Emmanuel Levinas », en Revue de métaphysique et de morale, $\mathrm{n}^{\circ} 3$.

LEVINAS, E. (1991) : Entre nous. Essais sur le penser-a-l'autre, Paris, Éditions Bernard Grasset. Entre Nosotros. Ensayos para pensar en otro, Salamanca, PreTextos, 2001.

Levinas, E. (1982a) : Ethique et infini, Paris, Fayard. Ética e infinito, Machado Libros, 1991.

LevinAs, E. (1982b) : L'Au-delà Du Verset, Paris, Éditions de Minuit. Más allá del versículo. Lecturas y discursos talmúdicos, Buenos Aires, Lilmod, 2006.

LevinAs, E. (2008): "La asimetría del rostro" en en Alonso Martos, A., (ed.), Emmanuel Levinas. La filosofía como ética, Universitat de València, PUV.

Levinas, E. (1980) : Le temps et l'Autre, Montpellier, Fata Morgana. El tiempo y el otro, Barcelona, Paidós, 1993.

Levinas, E. (1968) : Quatre lectures talmudiques, Paris, Edit. de Minuit. Cuatro lecturas talmúdicas, Riopiedras Ediciones, 1997.

Levinas, E. (1982c) : «Préface » en S. Mosès, Système et Révélation. La philosophie de Franz Rosenzweig, Paris, Éditions du Seuil.

Levinas, E. (2001) : Totalité et infini. Essai sur l'extériorité, Paris, Le livre de poche. Totalidad e infinito. Ensayo sobre la exterioridad, Valencia, Sígueme, 1999.

Levinas, E. (2006): Trascendencia e inteligibilidad. Seguido de una conversación, Madrid, Ediciones Encuentro.

LEVINAS, E. (2004): La teoría fenomenológica de la intuición, Valencia, Sígueme.

Mallet, M-L. (1998) : «Écouter un visage ?» en Rue Descartes. Emmanuel Lévinas, Paris, Quadrige / Puf.

NAnCy, J-L (1998) : «La voix sans nom » en Rue Descartes. Emmanuel Levinas, Paris, Quadrige / Puf.

Nordmann, S. (2008) : Philosophie et Judaïsme. H. Cohen, F. Rosenzweig, E. Levinas, Paris, Puf.

Peñalver, P. (2001): Argumento de alteridad. La hipérbole metafísica de Emmanuel Levinas. Madrid, Caparros 2001.

Peperzac, A. (2006): "Judaism and philosophy in Lévinas" en International Journal for Philosophy of Religion, vol. 40, $\mathrm{N}^{\circ} 3$ (Dec, 2006), pp. 125-145.

PÉrez QuintanA, A. (2008): "La crítica de Levinas a la filosofía trascendental moderna" en Martós, A. (comp. ), Emmanuel Levinas. La filosofía como ética, Universitat de València, Valencia.

Ricoeur, p. , (1953): « Sur la Phénoménologie », Esprit n. 21. 
Rosenzweig, F. (1997): La Estrella de la Redención, trad. Miguel García Baró, Sígueme, Salamanca.

Rosenzweig, F. (2005) El nuevo pensamiento, trad. Ángel García-Maturano, Buenos Aires, Adriana Hidalgo editora.

Scholem, G. (1971): The Messianic Idea in Judaism, New York, Schocken Books.

Scholem, G. (2006): "La idea mesiánica en la Cábala" en Y. T. Assis, M. Idel y L. Senkman, Ensayos sobre Cábala y Misticismo judío, Buenos Aires, Lilmod.

SucAsas, A. (2006): Levinas. Lecturas de un palimpsesto, Buenos Aires, Lilmod.

SuCASAS, A. (2002): Memoria de la ley: ensayos sobre el pensamiento judio, Barcelona, Riopiedras Ediciones.

Yerushalmi, Y. H. (2002): Zajor. La historia judía y la memoria judía, Madrid, Anthropos.

Ediciones de los textos sagrados cotejadas:

Biblia de Jerusalén, 1967.

Biblia del Peregrino, trad. A. Schökel, 1993

Santa Biblia. Reina Valera, El Paso, Editorial Mundo Hispano, 1989.

La Biblia. Versión castellana de León Dujovne, Manasés Konstantynowski y Moisés Konstantynowsky, Buenos Aires, ed. Sigal, 1973.

Talmud de Babilonia, versión hebreo-español, Editado por Abraham J. Weiss Versión castellana dirigida y redactada por Mario Calés, sobre la base de la edición de Vilna.

Babylonian Talmud, transl. Michael L. Rodkinson, Barnes Reference Library, 1903.

Gabriela Balcarce

Universidad de Buenos Aires

Consejo Nacional de Investigaciones Científicas y Técnicas

gabriela.balcarce@gmail.com 